\title{
Влияние антропогенных объектов на радиоэкологическое состояние почвенного покрова территории Новой Москвы
}

Гусева А.С. ${ }^{1}$, Петров В.А. ${ }^{1,2}$

${ }^{1}$ Институт геологии рудных месторождений, петрографии, минералогии и геохимии Российской академии наук (ИГЕМ РАН), Москва, alexandra.guseva2011@yandex.ru

${ }_{2}^{2}$ РХТУ им. Д.И. Менделеева, Москва, vlad243@igem.ru

Аннотация. В статье приводятся результаты исследований приповерхностного слоя почвенного покрова (до 10 см) территории Новой Москвы вблизи влияния антропогенных объектов. Пробы почвенного покрова проанализированы гамма-спектрометрическим методом на содержание радионуклидов $\left({ }^{137} \mathrm{Cs},{ }^{40} \mathrm{~K},{ }^{232} \mathrm{Th},{ }^{226} \mathrm{Ra}\right)$. Сделан вывод о влиянии тех или иных объектов хозяйственной деятельности на радиоэкологическое состояние почвенного покрова.

Ключевые слова: Новая Москва, анализ почв, радионуклиды, антропогенные объекты

\section{Influence of anthropogenic objects on the radioecological state of soil cover of the New Moscow territory}

\author{
Guseva A.S. ${ }^{1}$, Petrov V.A. ${ }^{2}$ \\ ${ }^{1}$ Institute of Geology of Ore Deposits, Petrography, Mineralogy and Geochemistry Russian Academy of \\ Sciences (IGEM RAS), Moscow, alexandra.guseva2011@yandex.ru \\ ${ }^{2}$ D. MendeleevUCTR, Moscow,vlad243@igem.ru
}

\begin{abstract}
In the article, the results of studies of a soil cover surface layer (up to $10 \mathrm{~cm}$ ) of the New Moscow territory near the influence of anthropogenic objects are presented. Soil cover samples were analyzed by gammaspectrometric method on content of radionuclides $\left({ }^{137} \mathrm{Cs},{ }^{40} \mathrm{~K},{ }^{232} \mathrm{Th},{ }^{226} \mathrm{Ra}\right)$. The conclusion was made about the influence of certain objects of economic activity on radioecological state of the soil cover.
\end{abstract}

Key words: New Moscow, analysis of soils, radionuclides, anthropogenic objects.

\section{Введение}

В настоящее время весьма актуальным является проведение исследований, направленных на оценку уровня современного радиационного загрязнения территории России. Однако для Московской области подобные работы до 2008 года практически не проводились (Цветнова и др., 2017). Новая Москва - это присоединенные к границам «старой» Москвы площади, которые до 2012 года входили в состав Московской области, и где также не проводилось изучения радиоэкологического состояния территории. Кроме того в пределах этой территории расположен ряд потенциально радиационно-опасных объектов, при работе которых в окружающую среду могут попадать как естественные $\left({ }^{40} \mathrm{~K},{ }^{238} \mathrm{U},{ }^{232} \mathrm{Th},{ }^{226} \mathrm{Ra}\right)$, так и искусственные $\left({ }^{137} \mathrm{Cs},{ }^{90} \mathrm{Sr}\right)$ радионуклиды, которые, будучи включенными в биологические миграционные цепочки, могут воздействовать на организм человека. Поэтому, в связи с развитием территории Новой Москвы проведение подобных исследований является крайне актуальным.

\section{Объект исследования}

В представленной работе объектом исследования является почвенный покров территории Новой Москвы в непосредственной близости от антропогенных объектов. Под антропогенными объектами понимаются здания, сооружения, инфраструктура, которые созданы людьми для осуществления хозяйственной деятельности. Пробы почвенного покрова отбирались на незначительном расстоянии от следующих антропогенных объектов: сельскохозяйственные поля, Троицкий институт инновационных и термоядерных исследований (ГНЦ РФ ТРИНИТИ), завод Мосрентген, полигон промышленных отходов «Летово». Необходимо отметить, что в границах Новой Москвы располо- 
жена крупная свалка ТКО - полигон «Саларьево», однако в связи с её рекультивацией отобрать пробы почвенного покрова вблизи неё не представлялось возможным. В пределах территории расположено большое количество сельскохозяйственных полей и ферм. Нами были отобраны пробы рядом с животноводческим комплексом Голохвастово и на сельскохозяйственных полях д. Рогово и Исаково. Полигон «Летово», созданный в 1964 г., расположенный в 7 км от г. Москвы по Калужскому шоссе, рядом с д. Макарово, в настоящее время закрыт. В 90-х годах XX века помимо твердых бытовых отходов, здесь проходило захоронение радиоактивных отходов, получаемых от организаций в г. Троицке.

\section{Методы исследования}

Отбор почвенных образцов проводился в соответствии с ГОСТ 17.4.3.01-83 «Охрана природы (ССОП). Почвы. Общие требования к отбору проб», ГОСТ 17.4.4.02-84 «Охрана природы. Почвы. Методы отбора и подготовки проб для химического, бактериологического, гельминтологического анализа», МУ 2.1.7.730-99 «Гигиеническая оценка качества почв населённых мест» с помощью ручного пробоотборника. Привязка места отбора проб осуществлялась с помощью GPS-приемника. Почвы отбирались в непосредственной близости от антропогенных источников: пять проб отбирались непосредственно на сельскохозяйственных полях (Г-хвост-19-1, Г-хвост-19-2, Ис-19-1, Рог-19-1, Рог-19-2), одна (Моср-н-19-1) на территории поселка завода Мосрентген, в 200 метров от полигона ТБО «Летово» (ТБО-19-1), в 600 и 800 метрах (Троицк-19-1 и Троицк-19-2) от ТРИНИТИ.

Отбор проб проводился на глубину 0-10 см, так как именно в этом слое сосредоточено почти 100 \% активности, обусловленной выпадениями из атмосферы. Объединенную пробу отбирали «методом конверта» путём смешивания точечных проб, отобранных на одной пробной площадке (ГОСТ «Охрана природы. ...»; Методические указания, 1999). Всего было отобрано 9 проб.

После отбора все почвы были высушены до воздушно-сухого состояния, удалены включения и корни растений, препятствующие получению корректных результатов.

Анализ проб почвенного покрова проводился в лаборатории радиогеологии и радиогеоэкологии ИГЕМ РАН (аналитики - Керзин А.Л., Соломенников Р.В.) с помощью прямого $\gamma$-спектрометрического анализа с использованием низкофонового $\gamma$-спектрометрического комплекса оснащенного $\mathrm{NaI}(\mathrm{Tl})$ детектором $160 \times 160$ мм с колодцами $55 \times 110$ мм. Метод основан на регистрации сцинтилляционным спектрометром гамма излучения, испускаемого веществом счетного образца в регламентированной геометрии, с последующей обработкой накопленных спектрограмм. Управление измерениями и обработка полученных спектров производится с использованием программного комплекса «СПЕКТР».

\section{Результаты исследования}

Все пробы были проанализированы на содержание следующих радионуклидов: ${ }^{137} \mathrm{Cs},{ }^{40} \mathrm{~K},{ }^{232} \mathrm{Th}$, ${ }^{226} \mathrm{Ra}$. Результаты анализа представлены в таблице 1.

В настоящее время содержание естественных и искусственных радионуклидов в почвах в российском законодательстве не нормируется. В случае отсутствия предельно допустимых концентраций (ПДК) сравнивают полученные значения с фоновыми значениями. В качестве фонового уровня используется региональный средний уровень (см. табл. 1) (Грицко, 2018).

Полученный аналитический материал был подвергнут статистической обработке в программном пакете «Microsoft Excel». Так как все выборки подчиняются закону нормального распределения (критерий Шапиро-Уилка, $\mathrm{p}>0.05$ ), то использовалась параметрическая статистика. В процессе статистической обработки данных получены следующие параметры: минимальные и максимальные значения выборки, среднее значение, стандартная ошибка и среднее отклонение, медиана и коэффициент вариации (табл. 2). 
Таблица 1. Удельная активность радионуклидов в местах отбора проб почвенного покрова (Бк/кг). Table 1 . The specific activity of radionuclides in places of the soil covers sampling $(\mathrm{Bk} / \mathrm{kg})$.

\begin{tabular}{|l|c|c|c|c|c|}
\hline \multicolumn{1}{|c|}{ Проба } & ${ }^{137} \mathrm{Cs}$ & ${ }^{40} \mathrm{~K}$ & ${ }^{226} \mathrm{Ra}$ & ${ }^{232} \mathrm{Th}$ & ${ }^{232} \mathrm{Th} /{ }^{226} \mathrm{Ra}$ \\
\hline Г-хвост-19-1 & 1.6 & 620 & 28 & 40 & 1.4 \\
\hline Г-хвост-19-2 & 4 & 580 & 26 & 37 & 1.4 \\
\hline Ис-19-1 & 1.4 & 630 & 29 & 42 & 1.4 \\
\hline Моср-н-19-1 & 5.4 & 590 & 28 & 40 & 1.4 \\
\hline Рог-19-1 & 1.3 & 620 & 28 & 45 & 1.6 \\
\hline Рог-19-2 & 2.2 & 630 & 29 & 46 & 1.6 \\
\hline ТБО-19-1 & 0 & 560 & 26 & 40 & 1.5 \\
\hline Троицк-19-1 & 8.5 & 600 & 27 & 40 & 1.5 \\
\hline $\begin{array}{l}\text { Троицк-19-2 } \\
\begin{array}{l}\text { Фоновое содержание } \\
\text { (Московский регион) }\end{array}\end{array}$ & 9 & 560 & 20 & 40 & $3 / 4$ \\
\hline $\begin{array}{l}\text { Среднемировые } \\
\text { фоновые содержания** }\end{array}$ & 2960 & 450 & 20 & 32.8 & $3 / 4$ \\
\hline
\end{tabular}

Примечание: *фоновое содержание (Московский регион) дано по (Лащенкова и др., 2006); **среднемировые фоновые содержания даны по (Цветнова и др., 2017).

Таблица 2. Некоторые статистические параметры удельной активности радионуклидов (Бк/кг) в местах отбора проб почвенного покрова.

Table 2. Some statistic parameters of specific activity of radionuclides $(\mathrm{Bk} / \mathrm{kg})$ in the places of the soil cover sampling.

\begin{tabular}{|l|c|c|c|c|}
\hline \multicolumn{1}{|c|}{ Параметр $\mathrm{n}=9$} & ${ }^{137} \mathrm{Cs}$ & ${ }^{40} \mathrm{~K}$ & ${ }^{226} \mathrm{Ra}$ & ${ }^{232} \mathrm{Th}$ \\
\hline Минимум & 0 & 560 & 26 & 37 \\
\hline Максимум & 8.5 & 630 & 29 & 46 \\
\hline Среднее & 3.6 & 606 & 27.7 & 41.3 \\
\hline Стандартное отклонение & 3.1 & 24.6 & 1.1 & 2.8 \\
\hline Ошибка среднего значения & 1.03 & 8.18 & 0.37 & 0.93 \\
\hline Медиана & 2.2 & 620 & 28 & 40 \\
\hline
\end{tabular}

Из таблиц 1 и 2 видно, что в некоторых местах отбора материала ${ }^{137} \mathrm{Cs}$ не был обнаружен, максимальная удельная активность радионуклида - 8.5 Бк/кг при среднем значении 3.6 Бк/кг. Результаты проведенных исследований выявили незначительный диапазон значений удельной активности естественных радионуклидов в почвах Новой Москвы: значения ${ }^{40} \mathrm{~K}$ находятся в пределах от 560 до 630 Бк/кг, при среднем 606 Бк/кг; значения ${ }^{226} \mathrm{Ra}-$ от 26 до 29 Бк/кг, при среднем значении 27.7 Бк/кг; минимальная удельная активность ${ }^{232} \mathrm{Th}$ составляет 37 Бк/кг, максимальная - 46 Бк/кг, при среднем значении - 41.3 Бк/кг.

Из всех этих радионуклидов только ${ }^{137} \mathrm{Cs}$ является искусственным радионуклидом, нахождение которого напрямую зависит от антропогенной деятельности человека. Видно, что во всех точках значение удельной активности ${ }^{137} \mathrm{Cs}$ не превышает фоновых региональных значений. Следовательно, рассмотренные антропогенные объекты не оказывают влияния на загрязнение почвенного покрова Новой Москвы этим радионуклидом. Незначительные содержания нуклида связаны с глобальными выпадениями и аварией на Чернобыльской АЭС, после которой среднемировые значения содержания ${ }^{137} \mathrm{Cs}$ в почвах возросли. Однако следует отметить, что максимальное содержание удельной активности ${ }^{137} \mathrm{Cs}$ характерно для почв, отобранных в 500 метрах от Троицкого института инновационных и термоядерных исследований и чем дальше от Института, тем активность це- 
зия уменьшается. Можно предположить, что эта организация оказывает незначительное негативное влияние на радиоэкологическое состояние почвенного покрова территории.

Что касается естественных радионуклидов, то их удельная активность незначительно превышает региональные фоновые значения, что говорит об относительно благоприятной радиоэкологической обстановке вблизи источников антропогенного влияния. Следует отметить, что максимальная удельная активность ${ }^{40} \mathrm{~K}$ характерна для почвы, отобранной на сельскохозяйственных полях и фермах, что может быть связано с внесением калийных удобрений, либо с накоплением ${ }^{40} \mathrm{~K}$ растительностью, поскольку он является постоянным спутником элемента-биофила - калия (Цветнова и др., 2017).

В целом на всех отобранных пробных площадках содержание радионуклидов находится на одном уровне (рис.).

Коэффициенты вариации (для ${ }^{40} \mathrm{~K}-4 \%,{ }^{226} \mathrm{Ra}-4.1 \%,{ }^{232} \mathrm{Th}-6.7 \%$ ) свидетельствуют о незначительном разбросе значений удельной активности в почве и об отсутствии явно выраженных аномальных участков.

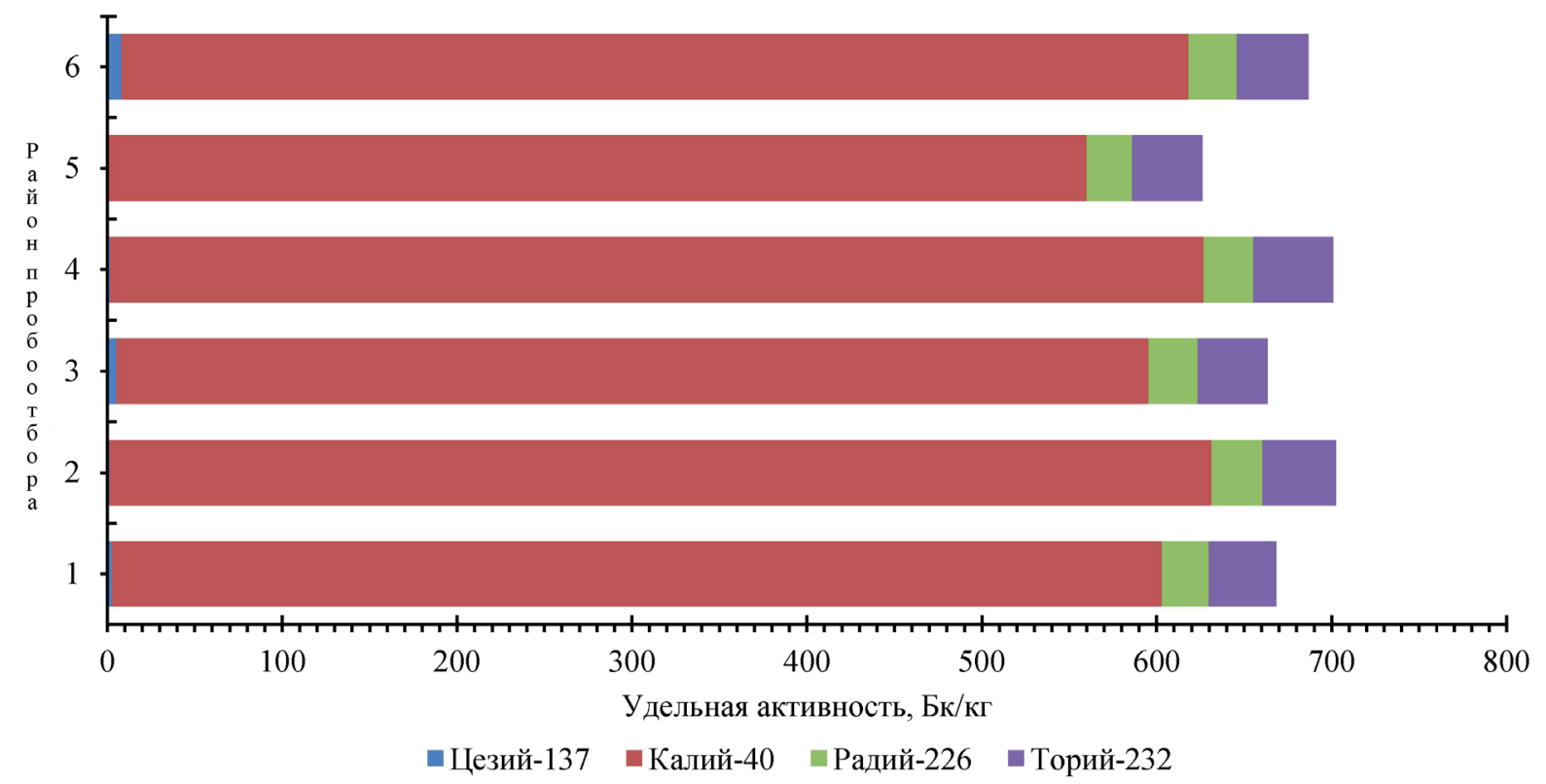

Рис. Содержание радионуклидов в почве в разных районах Новой Москвы.

1 - д. Голохвастово, 2 - д. Исаково, 3 - п. Мосрентген, 4 - д. Рогово, 5 - полигон «Летово», 6 - г. Троицк

Fig. The content of radionuclides in soil of the New Moscow different areas.

1 - village Golokhvastovo, 2 - village Isakovo, 3 - village Mosrentgen, 4 - village Rogovo, 5 - landfill "Letovo", 6 - town Troitsk.

В своей кандидатской диссертации Грицко П.П. рассматривает такой параметр как ${ }^{232} \mathrm{Th} / 226 \mathrm{Ra}$. Отношение значений активности ${ }^{232} \mathrm{Th} / 226 \mathrm{Ra}<1$ в почвах может служить индикатором техногенного вмешательства (Грицко, 2018). Из таблицы 1 видно, что для всех точек пробоотбора ${ }^{232} \mathrm{Th} /{ }^{226} \mathrm{Ra}>1$, т.е. рассмотренные антропогенные объекты территории Новой Москвы, скорее всего, не оказывают негативного влияния на радиоэкологическое состояние почвенного покрова.

В радиоэкологии основным параметром, характеризующим радиационную обстановку, принято считать радиогеохимическую характеристику компонента окружающей среды, которая определяется содержанием радионуклидов, выраженных в единицах удельной эффективной активности $\left(\mathrm{A}_{\text {эфф}}\right)$ :

$$
\mathrm{A}_{э ф \phi}=\mathrm{A}_{\mathrm{Ra}}+1.31 \mathrm{~A}_{\mathrm{Th}}+0.085 \mathrm{~A}_{\mathrm{K}},
$$

где $\mathrm{A}_{\mathrm{Ra}}, \mathrm{A}_{\mathrm{Th}}, \mathrm{A}_{\mathrm{K}}$ - удельные активности в Бк/кг изотопов ${ }^{226} \mathrm{Ra},{ }^{232} \mathrm{Th}$ и ${ }^{40} \mathrm{~K}$ соответственно (Грицко, 2018). 
Исходя из рассчитанных средних содержаний радионуклидов (табл. 2), средняя удельная активность почвенного покрова территории Новой Москвы вблизи источников антропогенного воздействия составляет 133.3 Бк/кг, что позволяет отнести исследуемую компоненту среды к потенциально опасному, но близко к безопасному (если $\mathrm{A}_{\text {эфф }}<100$, то объект исследования считается безопасным).

\section{Заключение}

В результате проведенного исследования было выявлено, что рассмотренные антропогенные объекты не оказывают отрицательного воздействия на радиоэкологическое состояние почвенного покрова территории Новой Москвы. Средние удельные активности ${ }^{40} \mathrm{~K},{ }^{226} \mathrm{Ra}$ и ${ }^{232} \mathrm{Th}$ незначительно превышают фоновые региональные значения, что не является критичным и не представляет большой опасности для здоровья людей. Удельная активность ${ }^{137} \mathrm{Cs}$ так же находится в пределах нормы.

В связи с этим в настоящее время не возникает острой необходимости в проведении более детального исследования вокруг антропогенных объектов территории Новой Москвы, что не исключает разработки и реализации процедур мониторинга.

\section{Благодарность}

Авторы выражают благодарность Болтневу М.В. и Пинаевской Е.А. за помощь в отборе проб почвенного покрова, Керзину А.Л. и Соломенникову Р.В. - за проведение гаммаспектрометрического анализа проб почвы.

\section{Литература}

1. ГОСТ 17.4.3.01-83. Охрана природы. Почвы. Общие требования к отбору проб // Охрана природы. Методические указания МУ 2.1.7.730-99. Гигиеническая оценка качества почвы населенных мест. М.: Санэпидиздат. $1999.26 \mathrm{c}$.

2. Грицко П.П. Распределение тория, урана и ${ }^{137} \mathrm{Cs}$ в почвах городов Иркутск и Ангарск (Прибайкалье): Дисс. .... канд. геол.-мин.наук. Иркутск. 2018. 148 с.

3. Лащенова Т.Н., Зозуль Ю.Н. Определение фонового содержания радионуклидов и тяжелых металлов в почве // Атомная энергия. 2006. Т. 100. Вып. 3. С. 230-236.

4. Методические указания МУ 2.1.7.730-99 «Гигиеническая оценка качества почвы населенных мест», 1999.

5. Цветнова О.Б., Манахов Д.В., Липатов Д.Н., Щеглов А.И. Радиоэкологическая характеристика территории учебно-опытного почвенно-экологического центра МГУ им. М.В. Ломоносова «Чашниково» // Вестник Московского университета. Серия 17. Почвоведение. 2017. № 3. С. 26-32. 